This is the peer reviewed accepted manuscript of the following article:

Walker AK, Martelli D, Ziegler Al, Lambert GW, Phillips SE, Hill SJ, McAllen RM, Sloan EK.

Circulating epinephrine is not required for chronic stress to enhance metastasis.

Psychoneuroendocrinology. 2019 Jan;99:191-195.

Final peer reviewed version available at: https://doi.org/10.1016/i.psyneuen.2018.09.012

Rights / License:

The terms and conditions for the reuse of this version of the manuscript are specified in the publishing policy. For all terms of use and more information see the publisher's website.

This item was downloaded from IRIS Università di Bologna (https://cris.unibo.it/)

When citing, please refer to the published version. 


\title{
Circulating epinephrine is not required for chronic stress to enhance metastasis
}

\author{
Adam K. Walker ${ }^{\# 1,2,3,4}$, Davide Martelli ${ }^{\# 5,6}$, Alexandra I. Ziegler ${ }^{1}$, Gavin W. Lambert ${ }^{7,8}$, \\ Sarah E. Phillips ${ }^{7,8}$, Stephen J. Hill ${ }^{9,10}$, Robin M. McAllen ${ }^{5}$, Erica K. Sloan ${ }^{1,2,11}$
}

\author{
\#Contributed equally \\ ${ }^{1}$ Drug Discovery Biology Theme, Monash Institute of Pharmaceutical Sciences, Monash \\ University, Parkville, Victoria 3052, Australia \\ ${ }^{2}$ Division of Cancer Surgery, Peter MacCallum Cancer Centre, East Melbourne, Victoria 3002, \\ Australia \\ ${ }^{3}$ Neuroscience Research Australia. Randwick, New South Wales, 2031, Australia \\ ${ }^{4}$ School of Psychiatry, University of New South Wales, Randwick, New South Wales, 2031, \\ Australia \\ ${ }^{5}$ Florey Institute of Neuroscience and Mental Health, University of Melbourne, Parkville, Victoria \\ 3052, Australia \\ ${ }^{6}$ Department of Biomedical and Neuromotor Science, University of Bologna, Bologna, Italy. \\ ${ }^{7}$ Iverson Health Innovation Research Institute, Faculty of Health Arts and Design, Swinburne \\ University of Technology, Hawthorn, Victoria 3122, Australia \\ ${ }^{8}$ Human Neurotransmitters Laboratory, Baker Heart \& Diabetes Institute, Melbourne, Victoria \\ 3004, Australia \\ ${ }^{9}$ Division of Physiology, Pharmacology and Neuroscience, School of Life Sciences, University of \\ Nottingham, Nottingham, NG7 2UH, UK \\ ${ }^{10}$ Centre of Membrane Proteins and Receptors, University of Birmingham and University of \\ Nottingham, The Midlands, UK \\ ${ }^{11}$ Cousins Center for PNI, UCLA Semel Institute, Jonsson Comprehensive Cancer Center, and \\ UCLA AIDS Institute, University of California Los Angeles, Los Angeles, CA 90095, USA
}

Key words: epinephrine, norepinephrine, cancer, stress-enhanced metastasis, splanchnic nerve, inflammatory reflex

Running title: Epinephrine and breast cancer progression

\section{HIGHLIGHTS}

- Chronic stress enhances cancer progression including metastasis in mouse models of breast cancer

- Splanchnic nerve lesioning eliminates epinephrine release from the adrenal medulla

- Circulating epinephrine does not affect stress-enhanced cancer progression 
Signaling through $\beta$-adrenergic receptors drives cancer progression and $\beta$-blockers are being evaluated as a novel therapeutic strategy to prevent metastasis. Orthotopic mouse models of breast cancer show that $\beta$-adrenergic signaling induced by chronic stress accelerates metastasis, and that $\beta_{2}$-adrenergic receptors on tumor cells are critical for this. Endogenous catecholamines are released during chronic stress: norepinephrine from the adrenal medulla and sympathetic nerves, and epinephrine from the adrenal medulla. $\beta_{2}$-adrenergic receptors are much more sensitive to epinephrine than to norepinephrine. To determine if epinephrine is necessary in the effects of stress on cancer progression, we used a denervation strategy to eliminate circulating epinephrine, and quantified the effect on metastasis. Using both human xenograft and immune-intact murine models of breast cancer, we show that circulating epinephrine is dispensable for the effects of chronic stress on cancer progression. Measured levels of circulating norepinephrine were sufficiently low that they were unlikely to influence $\beta_{2}$-adrenergic signaling, suggesting a possible role for norepinephrine release from sympathetic nerve terminals. 


\section{INTRODUCTION}

Beta-adrenergic receptor ( $\beta \mathrm{AR})$ signaling has been identified as a target to modulate cancer progression. Preclinical studies in many types of cancer found that $\beta A R$ signaling drives cancer progression, and identified molecular and cellular mechanisms (Thaker et al., 2006, Nissen et al., 2018, Le et al., 2016, Kim-Fuchs et al., 2014, Lamkin et al., 2012, Sloan et al., 2010, Kim et al., 2016). These studies discovered that $\beta A R$ signaling in tumor cells drives tumor cell invasion by enhancing formation of invadopodia, resulting in increased metastasis in vivo (Chang et al., 2016, Pon et al., 2016, Kim et al., 2016, Creed et al., 2015). Stromal cells in the tumor microenvironment also are responsive to $\beta \mathrm{AR}$ signaling. Both innate and adaptive immune cells express $\beta_{2} \mathrm{AR}$ (Nissen et al., 2018). $\beta A R$ signaling in tumor-associated macrophages remodels vasculature to increase routes for tumor cell dissemination (Le et al., 2016, Sloan et al., 2010, Thaker et al., 2006), while $\beta A R$ signaling in CD8+ cytotoxic T cells impairs anti-tumor immunity, which accelerates cancer and impairs immunotherapy (Bucsek et al., 2017, Kokolus et al., 2018, Nissen et al., 2018).

As a consequence of these findings, $\beta$-blockers are being evaluated as a novel strategy to slow cancer progression. Epidemiological studies have shown an association between $\beta$-blocker use and reduced metastasis (Watkins et al., 2015, Choi et al., 2014, Melhem-Bertrandt et al., 2011, Powe et al., 2010, Botteri et al., 2013, De Giorgi et al., 2013), although not in all cohorts (Sorensen et al., 2013), and two prospective clinical studies have demonstrated that $\beta$-blockers reduce biomarkers of metastasis and improve survival (Shaashua et al., 2017, De Giorgi et al., 2017). A number of ongoing clinical studies are now evaluating $\beta$-blocker use in the perioperative period to prevent cancer recurrence after tumor-resection surgery (Hiller et al., 2017, Horowitz et al., 2015).

Signaling through $\beta \mathrm{AR}$ is induced by endogenous catecholamines; epinephrine and norepinephrine. The adrenal medulla is the main source of epinephrine (Esler et al., 1988, Esler et al., 1990), with neurotransmitter release tightly controlled by the splanchnic nerve (de Diego et al., 2008). The main source of norepinephrine is nerve terminals of the post-ganglionic sympathetic nervous system (SNS) 
that are present in peripheral organs including the breast (Eriksson et al., 1996, Furlan et al., 2016). A number of studies have demonstrated a critical role for signalling through the $\beta_{2} \mathrm{AR}$ receptor subtype in the effects of stress on cancer progression (Chang et al., 2016, Nissen et al., 2018, Thaker et al., 2006). $\beta_{2} \mathrm{AR}$ binds epinephrine with approximately 10 -fold greater affinity than norepinephrine $\left(\mathrm{pK} \mathrm{D}_{\mathrm{D}}=6.13\right.$ vs. 5.41) (Baker, 2010). Therefore, to investigate the necessity of circulating epinephrine in the effect of stress on cancer progression, we used a denervation strategy to block the supply of epinephrine from the adrenal medulla into circulation, and examined the impact on breast cancer metastasis. 


\section{METHODS}

2.1. Animals. Female BALB/c nu/nu (Animal Resources Centre, Western Australia) and BALB/c mice (Monash University, Australia) were housed in a temperature and humidity controlled environment with a 12/12-h dark-light cycle. Food and water were available ad libitum. Mice were acquired at 6 weeks old and were given 1-2 weeks to acclimate before experimentation commenced with denervation surgery. Surgery was conducted from 7-8 weeks of age for studies in BALB/c mice, and at 8-9 weeks for studies in BALB/c nu/nu mice. All procedures involving mice were carried out under protocols approved by the Institutional Animal Ethics Committee and in accordance with National Health and Medical Research Council guidelines.

2.2. Denervation. The greater splanchnic nerves were exposed retroperitoneally on each side, as described previously for rats (Martelli et al., 2014a). The nerves were either cut bilaterally just beneath the diaphragm (Denervation group) or left intact (Sham group). Specifically, surgical access to the right nerve was made through a right flank incision $(1-1.5 \mathrm{~cm})$ below the ribs but above the pelvis, close to the back muscles. Incision of the thin muscle sheet next to the back muscles revealed the retroperitoneal space (including the kidney, adrenal gland and peri-renal fat), which was opened with blunt separation and retraction while keeping the peritoneum intact. The adrenal gland was pulled downwards with a cotton bud to expose the splanchnic nerve, which was separated with fine forceps and then cut. The central branch was peeled away to eliminate the possibility of nerve regeneration. The left splanchnic nerve was cut by the mirror image procedure through a second incision. The incisions were closed by suturing and mice allowed to heal for four days prior to starting restraint stress. Surgery was performed under isoflurane anaesthesia ( $2 \%$ in oxygen).

2.3. Cell culture. The human metastatic breast cancer cell line MDA-MB-231 ${ }^{\mathrm{HM}}$ (Le et al., 2016) was cultured in DMEM-GlutaMAX media (Life Technologies), and the 66cl4 luminal B mammary adenocarcinoma cell line (Sloan et al., 2010) was cultured in aMEM-GlutaMAX media (Life 
Technologies). All media was supplemented with 10\% fetal bovine serum (Life Technologies). All cells were maintained at $37^{\circ} \mathrm{C}$ and $5 \% \mathrm{CO}_{2}$ and mycoplasma tested before injection using primers as described (Uphoff and Drexler, 2002). Cell line identities were confirmed by short tandem repeat profiling (Cellbank, Australia). All cells have been stably transduced with a non-replicating lentiviral construct containing luc2 (codon optimised luciferase) under control of the ubiquitin $\mathrm{C}$ promoter to allow in vivo monitoring (see below) with either mCherry or eGFP fluorescent protein for further analysis.

2.4. Animal breast cancer models. Either $2 \times 10^{5} \mathrm{MDA}-\mathrm{MB}-231^{\mathrm{HM}}$ cells or $1 \times 10^{5} 66 \mathrm{cl} 4$ cells in $20 \mu \mathrm{L}$ PBS (Invitrogen) were injected into the $4^{\text {th }}$ inguinal mammary fat pad of anesthetized (3\% isoflurane) $\mathrm{BALB} / \mathrm{c} n u / n u$ or BALB/c mice respectively. Primary tumor growth was monitored by digital caliper twice a week and volume calculated using the formula: (length $\mathrm{x}$ width $\left.{ }^{2}\right) / 2$. Further, growth and metastasis of luciferase-tagged tumor cells were tracked non-invasively in mice with bioluminescence with Living Image Software on an IVIS Lumina II (Perkin Elmer) imaging system after mice received $150 \mathrm{mg} / \mathrm{kg}$ D-luciferin (Choice analytical) in $100 \mu \mathrm{L}$ PBS via the tail vein. During the experiment, blood was collected at various time points in vials containing EGTA (Sigma-Aldrich) for catecholamine analysis. Plasma was collected after centrifugation at $1000 \mathrm{~g}, 4^{\circ} \mathrm{C}$, and immediately snap frozen in liquid nitrogen.

2.5. Physiological activation of the SNS stress response. To physiologically activate neural signaling, mice were placed in a restraint apparatus for two hours per day for 21 consecutive days, starting five days prior to tumor cell injection (Thaker et al., 2006, Sloan et al., 2010, Le et al., 2016). This protocol has been previously used to demonstrate regulation of metastasis by stress in mouse models of breast cancer and other cancers (Le et al., 2016, Thaker et al., 2006, Kim-Fuchs et al., 2014, Sloan et al., 2010). Briefly, each mouse was placed into a well-ventilated compartment, and the space 
in each compartment was adjusted according to the length of each individual mouse so mice were maintained in a confined space (final dimensions: $30 \times 28$ x $40 \mathrm{~mm}$ ).

2.6. Catecholamine analysis. Blood was collected from the submandibular vein four days after splanchnic denervation and again immediately after the third session of daily restraint. Blood was collected into chilled tubes containing EGTA and reduced glutathione, and plasma for catecholamine analysis was immediately separated by centrifugation at $4^{\circ} \mathrm{C}$ and snap frozen in liquid nitrogen without delay. Samples were stored at $-80^{\circ} \mathrm{C}$ and analyzed by HPLC within 35 days of sample collection. Sampling, processing and storage of plasma according to these methods is associated with little change in catecholamines and metabolites (Lambert et al., 1991, Venneri and Del Rio, 2004). Catecholamines were extracted from plasma with alumina adsorption, separated by high-performance liquid chromatography, and quantified by coulometric detection according to previously described methods (Lambert and Jonsdottir, 1998).

2.7. Statistical analysis. All data are presented as means \pm SE. Statistical differences in individual catecholamines were determined using Mann-Whitney Tests. Longitudinal analyses for primary tumor growth and metastasis were determined using Repeated Measures Analyses of Variance (ANOVA). Post-hoc analyses were conducted using Tukey's multiple comparison test. GraphPad Prism software, version 7 was used for data presentation and analysis. 


\section{RESULTS}

Action potentials in pre-ganglionic nerve fibers regulate release of epinephrine from the adrenal medulla. Therefore, cutting the splanchnic nerve prevents epinephrine release from the adrenal medulla. To determine if bilateral splanchic denervation was effective, we used HPLC to quantify the levels of circulating catecholamines in plasma of mice 4 days after denervation surgery. Denervation of the splanchnic nerves abrogated circulating epinephrine, reducing it by 20 -fold compared to sham-operated controls (median sham vs denervated: $1732 \mathrm{vs} .89 \mathrm{pg} / \mathrm{ml}, U=0, p<$ $0.05)$ but did not affect plasma norepinephrine $(p>0.05)$ (Fig 1).

Under conditions of stress or fear, there is a surge of catecholamine release from the adrenal medulla and SNS nerves, which mobilizes the body for the 'fight-or-flight' response. To investigate if splanchic denervation eliminated the circulating epinephrine response to stress, plasma catecholamines were also assessed after induction of chronic stress by repeated daily restraint. Stress increased plasma epinephrine in sham-operated mice by 2.2 -fold $(1.73 \mathrm{vs} .3 .72 \mathrm{ng} / \mathrm{ml}, U=0$, $p<0.05)$, but had no effect on circulating epinephrine in denervated mice $(0.09 \mathrm{vs} 0.11 \mathrm{ng} / \mathrm{ml}, p>$ 0.05)(Fig 2A). In contrast, stress increased circulating norepinephrine levels in both sham-operated and denervated mice compared to baseline (1.6-4-fold, $\mathrm{U}=20, p<0.05)($ Fig $2 \mathrm{~B})$. There was no difference in stress-induced norepinephrine concentrations between denervated and sham-treated mice. To ensure that these findings were not confounded by metabolism by monoaminoxidase we assessed plasma dihydroxyphenylglycol (DHPG) concentration. DHPG was detected but levels were not affected by denervation or restraint stress ( $p$ > 0.05) (Supplementary Figure 1).

Collectively, these findings show that splanchnic denervation blocks baseline epinephrine release under resting conditions and prevents physiological elevation of epinephrine in response to stress.

Chronic stress acts through $\beta$ AR signaling to enhance tumor growth and metastasis in mouse models of breast cancer (Le et al., 2016, Chang et al., 2016). To determine the necessity of plasma epinephrine in cancer progression, we investigated the effect of stress on metastasis in denervated mice. Human 
MDA-MB-231 ${ }^{\mathrm{HM}}$ breast cancer cells were injected into the mammary fatpad of mice after splanchnic or sham surgery. Mice were then exposed to chronic stress or control conditions during tumor development, as previously described (Le et al., 2016, Sloan et al., 2010). In mice with intact splanchnic nerves, stress enhanced primary tumor growth (Fig 3A) and metastasis (Fig 3B), consistent with previous findings (Le et al., 2016, Chang et al., 2016). Elimination of plasma epinephrine by splanchnic nerve denervation had no effect on stress-enhanced primary tumor growth or metastasis, indicating that circulating epinephrine is not necessary for breast cancer progression (Fig 3).

Increasing evidence shows the importance of the adaptive immune response in regulating cancer progression (de Visser et al., 2006). We recently discovered that $\beta A R$ signaling regulates CD8+ T cells to control anti-tumor immunity (Nissen et al., 2018). As the MDA-MB-231 ${ }^{\mathrm{HM}}$ cell-line requires assessment in nude mice, which lack functional $\mathrm{T}$ cells (Fig 3), we evaluated if epinephrine contributes to cancer progression in mice with intact and functional T cells. $66 \mathrm{cl} 4$ cells express $\beta \mathrm{AR}$ and chronic stress drives metastasis in this model (Sloan et al., 2010, Pon et al., 2016). Balb/c mice were injected with $66 \mathrm{cl} 4$ tumor cells, which are syngenic in this immunocompetent mouse strain. Denervation had no effect on primary tumor growth or metastasis (Fig 4A, B), confirming that circulating epinephrine is dispensable for breast cancer progression under stress conditions. 


\section{DISCUSSION}

Despite a wealth of evidence that neural signaling through $\beta$-adrenergic receptors drives breast cancer progression (Sloan et al., 2010, Le et al., 2016, Chang et al., 2016, Creed et al., 2015, Kim-Fuchs et al., 2014, Lamkin et al., 2012) the endogenous catecholaminergic neurotransmitter(s) responsible for activating $\beta A R$ and the source of neurotransmitter release are unknown. Here we use denervation of the splanchnic nerve to selectively deplete plasma epinephrine, and demonstrate for the first time that circulating epinephrine is not required for neural regulation of breast cancer.

The findings suggest that it is unlikely that plasma catecholamines drive cancer progression. Antagonist studies using $\beta$-blockers have demonstrated that neural signaling promotes metastasis by activating $\beta$ AR that are present on tumor cells (Chang et al., 2016, Creed et al., 2015, Sood et al., 2010) and on cells in the tumor microenvironment (Le et al., 2016, Nissen et al., 2018, Sloan et al., 2010). In particular, $\beta_{2} \mathrm{AR}$ on tumor cells and immune cells are important for the effect of stress on breast cancer progression (Chang et al., 2016, Le et al., 2016, Nissen et al., 2018). Epinephrine binds preferentially to $\beta_{2} \mathrm{AR}$ (circa 10 -fold selectivity for $\beta_{2} \mathrm{AR}$ over $\beta_{1} \mathrm{AR}$ ) and has a higher affinity for this receptor $\left(\mathrm{pK}_{\mathrm{D}}=6.13\right)$ than norepinephrine $\left(\mathrm{pK}_{\mathrm{D}}=5.41\right)$ (Baker, 2010). We found however, that the epinephrine levels available in the plasma of mice with intact splanchnic nerves were low (2$4 \mathrm{ng} / \mathrm{ml}$, i.e., circa 10-20 nM), which would occupy only a very small fraction of the $\beta_{2} \mathrm{AR}$ on target cells. As such, the low occupancy of $\beta_{2} \mathrm{AR}$ achieved by circulating epinephrine means that any resulting signaling will depend on the agonist efficacy of epinephrine, and the signaling amplification and receptor expression level of the target cells. The fact that circulating epinephrine is not required for neural regulation of cancer progression strongly suggests that signaling efficiency and $\beta_{2} \mathrm{AR}$ expression in the relevant target cells is not sufficiently high for plasma epinephrine to have a major influence on their intracellular signaling. Even under stress conditions, norepinephrine in plasma only reached nanomolar levels (mean: 4 ng/ml, i.e., circa $20 \mathrm{nM}$; Figure 2), suggesting that it is most unlikely that circulating norepinephrine (which has a similar agonist efficacy to epinephrine at $\beta_{2} \mathrm{AR}$; (Baker, 2010)) impacted $\beta A R$ signaling sufficiently to drive cancer progression. 
These findings suggest that a likely source of neurotransmitter to drive breast cancer progression is the local release of norepinephrine from SNS nerve terminals. The normal breast (or mammary gland) is innervated (Eriksson et al., 1996) and catecholaminergic nerve fibers have been detected in both human tumours and mouse models of cancer (Szpunar et al., 2016, Cole et al., 2010, Allen et al., 2018). There is some evidence that breast tumor cells induce neo-neurogenesis through nerve growth factor-mediated mechanism (Boilly et al., 2017). Notably, social isolation has been linked to elevated levels of norepinephrine in tumours of ovarian cancer patients, consistent with the idea that chronic stress impacts neural signalling in cancers (Lutgendorf et al., 2011). Additionally, immune cells that are recruited to tumors and influence tumour progression may be exposed to neurotransmitters outside the primary tumor. For example, myeloid cells may be exposed to neurotransmitters in the bone marrow (Hanoun et al., 2015). There is growing understanding that SNS neural signaling in the bone marrow modulates immune function in ways that impact cancer progression (Maryanovich et al., 2018, Ben-Shaanan et al., 2018, Sloan et al., 2010, Le et al., 2016).

The finding that splanchnic denervation did not alter breast cancer progression is consistent with high levels of inflammation in aggressive cancer (de Visser et al., 2006). We recently characterised the critical role of the splanchnic nerve in the inflammatory reflex, which limits the acute inflammatory response (Martelli et al., 2014a, Martelli et al., 2016). We found that lesioning the splanchnic nerve releases the brakes on inflammation, resulting in significant amplification of pro-inflammatory cytokine levels in response to an immune challenge (Martelli et al., 2014a, Martelli et al., 2014b). Inflammation is known to drive cancer progression, and neural signaling through $\beta \mathrm{AR}$ controls the phenotype of macrophages and their recruitment to tumors to accelerate metastasis (Sloan et al., 2010, Le et al., 2016, de Visser et al., 2006, Lamkin et al., 2016). This raises the possibility of opposing actions of epinephrine - regulated by the splanchnic nerve to control inflammation - and norepinephrine - released from local nerve terminals to drive tumor-associated inflammation and therefore cancer progression. This possibility is not directly tested here and will be followed up in future studies. 
In sum, these findings show that circulating epinephrine is not necessary for the effects of stress on breast cancer progression, despite its greater affinity to $\beta_{2} \mathrm{AR}$ compared to norepinephrine. Future studies will characterize the sources of catecholamines that mediate the neural regulation of cancer, including tumor and lymphoid innervation, as well as possible contributions from immune cells.

\section{CONFLICT OF INTEREST}

The authors declare no conflicts of interest in relation to this manuscript. The laboratory of Gavin Lambert has recently received research funding from Medtronic. Professor Lambert has acted as a consultant for Medtronic and has received honoraria or travel support for presentations from Pfizer, Wyeth Pharmaceuticals, Servier and Medtronic. Erica Sloan is on the SAB for Cygnal Therapeutics.

\section{ACKNOWLEDGMENTS:}

This work was supported by a National Breast Cancer Foundation Australia postdoctoral fellowship (PF-15-014) and a Monash Interdisciplinary Research Scheme Award to AKW; the David and Lorelle Skewes Foundation, the Peter Mac Foundation, and the National Health and Medical Research Council (APP1147498, APP1098887). GL was supported by a Senior Research Fellowship from the NHMRC (APP1042492). This work was supported by the Victorian Government's Operational Infrastructure Support Program. 


\section{REFERENCES}

Allen, J. K., Armaiz-Pena, G. N., Nagaraja, A. S., Sadaoui, N. C., Ortiz, T., Dood, R., Ozcan, M., Herder, D. M., Haemerrle, M., Gharpure, K. M., Rupaimoole, R., Previs, R., Wu, S. Y., Pradeep, S., Xu, X., Dong Han, H., Zand, B., Dalton, H. J., Taylor, M., Hu, W., BottsfordMiller, J., Moreno-Smith, M., Kang, Y., Mangala, L. S., Rodriguez-Aguayo, C., Sehgal, V., Spaeth, E. L., Ram, P. T., Wong, S. T., Marini, F. C., Lopez-Berestein, G., Cole, S. W., Lutgendorf, S. K., Dibiasi, M. \& Sood, A. K. 2018. Sustained adrenergic signaling promotes intratumoral innervation through BDNF induction. Cancer Res.

Baker, J. G. 2010. The selectivity of beta-adrenoceptor agonists at human beta1-, beta2- and beta3adrenoceptors. Br J Pharmacol, 160, 1048-61.

Ben-Shaanan, T. L., Schiller, M., Azulay-Debby, H., Korin, B., Boshnak, N., Koren, T., Krot, M., Shakya, J., Rahat, M. A., Hakim, F. \& Rolls, A. 2018. Modulation of anti-tumor immunity by the brain's reward system. Nat Commun, 9, 2723.

Boilly, B., Faulkner, S., Jobling, P. \& Hondermarck, H. 2017. Nerve Dependence: From Regeneration to Cancer. Cancer Cell, 31, 342-354.

Botteri, E., Munzone, E., Rotmensz, N., Cipolla, C., De Giorgi, V., Santillo, B., Zanelotti, A., Adamoli, L., Colleoni, M., Viale, G., Goldhirsch, A. \& Gandini, S. 2013. Therapeutic effect of beta-blockers in triple-negative breast cancer postmenopausal women. Breast Cancer Res Treat, 140, 567-75.

Bucsek, M. J., Qiao, G., Macdonald, C. R., Giridharan, T., Evans, L., Niedzwecki, B., Liu, H., Kokolus, K. M., Eng, J. W.-L., Messmer, M. N., Attwood, K., Abrams, S. I., Hylander, B. L. \& Repasky, E. A. 2017. $\beta$-adrenergic signaling in mice housed at standard temperatures suppresses an effector phenotype in CD8+ T cells and undermines checkpoint inhibitor therapy.

Chang, A., Le, C. P., Walker, A. K., Creed, S. J., Pon, C. K., Albold, S., Carroll, D., Halls, M. L., Lane, J. R., Riedel, B., Ferrari, D. \& Sloan, E. K. 2016. beta2-Adrenoceptors on tumor cells play a critical role in stress-enhanced metastasis in a mouse model of breast cancer. Brain Behav Immun, 57, 106-15.

Choi, C. H., Song, T., Kim, T. H., Choi, J. K., Park, J. Y., Yoon, A., Lee, Y. Y., Kim, T. J., Bae, D. S., Lee, J. W. \& Kim, B. G. 2014. Meta-analysis of the effects of beta blocker on survival time in cancer patients. J Cancer Res Clin Oncol, 140, 1179-88.

Cole, S. W., Arevalo, J. M., Takahashi, R., Sloan, E. K., Lutgendorf, S. K., Sood, A. K., Sheridan, J. F. \& Seeman, T. E. 2010. Computational identification of gene-social environment interaction at the human IL6 locus. Proc Natl Acad Sci U S A, 107, 5681-6.

Creed, S. J., Le, C. P., Hassan, M., Pon, C. K., Albold, S., Chan, K. T., Berginski, M. E., Huang, Z., Bear, J. E., Lane, J. R., Halls, M. L., Ferrari, D., Nowell, C. J. \& Sloan, E. K. 2015. beta2adrenoceptor signaling regulates invadopodia formation to enhance tumor cell invasion. Breast Cancer Res, 17, 145.

De Diego, A. M., Gandia, L. \& Garcia, A. G. 2008. A physiological view of the central and peripheral mechanisms that regulate the release of catecholamines at the adrenal medulla. Acta Physiol (Oxf), 192, 287-301.

De Giorgi, V., Gandini, S., Grazzini, M., Benemei, S., Marchionni, N. \& Geppetti, P. 2013. Effect of beta-blockers and other antihypertensive drugs on the risk of melanoma recurrence and death. Mayo Clin Proc, 88, 1196-203.

De Giorgi, V., Grazzini, M., Benemei, S., Marchionni, N., Botteri, E., Pennacchioli, E., Geppetti, P. \& Gandini, S. 2017. Propranolol for Off-Label Treatment of Patients With Melanoma: Results From a Cohort Study. JAMA Oncol.

De Visser, K. E., Eichten, A. \& Coussens, L. M. 2006. Paradoxical roles of the immune system during cancer development. Nature Reviews Cancer, 6, 24. 
Eriksson, M., Lindh, B., Uvna“S-Moberg, K. \& Ho“Kfelt, T. 1996. Distribution and origin of peptide-containing nerve fibres in the rat and human mammary gland. Neuroscience, 70, 227-245.

Esler, M., Jennings, G., Korner, P., Willett, I., Dudley, F., Hasking, G., Anderson, W. \& Lambert, G. 1988. Assessment of human sympathetic nervous system activity from measurements of norepinephrine turnover. Hypertension, 11, 3-20.

Esler, M., Jennings, G., Lambert, G., Meredith, I., Horne, M. \& Eisenhofer, G. 1990. Overflow of catecholamine neurotransmitters to the circulation: source, fate, and functions. Physiol Rev, 70, 963-85.

Furlan, A., La Manno, G., Lübke, M., Häring, M., Abdo, H., Hochgerner, H., Kupari, J., Usoskin, D., Airaksinen, M. S., Oliver, G., Linnarsson, S. \& Ernfors, P. 2016. Visceral motor neuron diversity delineates a cellular basis for nipple- and pilo-erection muscle control. Nature Neuroscience, 19, 1331.

Hanoun, M., Maryanovich, M., Arnal-Estapé, A. \& Frenette, P. S. 2015. Neural regulation of hematopoiesis, inflammation and cancer. Neuron, 86, 360-373.

Hiller, J. G., Perry, N. J., Poulogiannis, G., Riedel, B. \& Sloan, E. K. 2017. Perioperative events influence cancer recurrence risk after surgery. Nature Reviews Clinical Oncology, 15, 205.

Horowitz, M., Neeman, E., Sharon, E. \& Ben-Eliyahu, S. 2015. Exploiting the critical perioperative period to improve long-term cancer outcomes. Nat Rev Clin Oncol, 12, 213-26.

Kim-Fuchs, C., Le, C. P., Pimentel, M. A., Shackleford, D., Ferrari, D., Angst, E., Hollande, F. \& Sloan, E. K. 2014. Chronic stress accelerates pancreatic cancer growth and invasion: a critical role for beta-adrenergic signaling in the pancreatic microenvironment. Brain, behavior, and immunity, 40, 40-47.

Kim, T.-H., Gill, N. K., Nyberg, K. D., Nguyen, A. V., Hohlbauch, S. V., Geisse, N. A., Nowell, C. J., Sloan, E. K. \& Rowat, A. C. 2016. Cancer cells become less deformable and more invasive with activation of $\beta$-adrenergic signaling. Journal of Cell Science, 129, 4563-4575.

Kokolus, K. M., Zhang, Y., Sivik, J. M., Schmeck, C., Zhu, J., Repasky, E. A., Drabick, J. J. \& Schell, T. D. 2018. Beta blocker use correlates with better overall survival in metastatic melanoma patients and improves the efficacy of immunotherapies in mice.

OncoImmunology, 7, e1405205.

Lambert, G. W., Eisenhofer, G., Cox, H. S., Horne, M., Kalff, V., Kelly, M., Jennings, G. L. \& Esler, M. D. 1991. Direct determination of homovanillic acid release from the human brain, an indicator of central dopaminergic activity. Life Sci, 49, 1061-72.

Lambert, G. W. \& Jonsdottir, I. H. 1998. Influence of voluntary exercise on hypothalamic norepinephrine. J Appl Physiol (1985), 85, 962-6.

Lamkin, D. M., Ho, H.-Y., Ong, T. H., Kawanishi, C. K., Stoffers, V. L., Ahlawat, N., Ma, J. C. Y., Arevalo, J. M. G., Cole, S. W. \& Sloan, E. K. 2016. $\beta$-Adrenergic-stimulated macrophages: Comprehensive localization in the M1-M2 spectrum. Brain, Behavior, and Immunity, 57, 338-346.

Lamkin, D. M., Sloan, E. K., Patel, A. J., Chiang, B. S., Pimentel, M. A., Ma, J. C., Arevalo, J. M., Morizono, K. \& Cole, S. W. 2012. Chronic stress enhances progression of acute lymphoblastic leukemia via beta-adrenergic signaling. Brain Behav Immun, 26, 635-41.

Le, C. P., Nowell, C. J., Kim-Fuchs, C., Botteri, E., Hiller, J. G., Ismail, H., Pimentel, M. A., Chai, M. G., Karnezis, T., Rotmensz, N., Renne, G., Gandini, S., Pouton, C. W., Ferrari, D., Moller, A., Stacker, S. A. \& Sloan, E. K. 2016. Chronic stress in mice remodels lymph vasculature to promote tumour cell dissemination. Nat Commun, 7.

Lutgendorf, S. K., Degeest, K., Dahmoush, L., Farley, D., Penedo, F., Bender, D., Goodheart, M., Buekers, T. E., Mendez, L., Krueger, G., Clevenger, L., Lubaroff, D. M., Sood, A. K. \& Cole, S. W. 2011. Social isolation is associated with elevated tumor norepinephrine in ovarian carcinoma patients. Brain Behav Immun, 25, 250-5.

Martelli, D., Farmer, D. G. \& Yao, S. T. 2016. The splanchnic anti-inflammatory pathway: could it be the efferent arm of the inflammatory reflex? Exp Physiol, 101, 1245-1252. 
Martelli, D., Yao, S. T., Mancera, J., Mckinley, M. J. \& Mcallen, R. M. 2014a. Reflex control of inflammation by the splanchnic anti-inflammatory pathway is sustained and independent of anesthesia. Am J Physiol Regul Integr Comp Physiol, 307, R1085-91.

Martelli, D., Yao, S. T., Mckinley, M. J. \& Mcallen, R. M. 2014b. Reflex control of inflammation by sympathetic nerves, not the vagus. J Physiol, 592, 1677-86.

Maryanovich, M., Zahalka, A. H., Pierce, H., Pinho, S., Nakahara, F., Asada, N., Wei, Q., Wang, X., Ciero, P., Xu, J., Leftin, A. \& Frenette, P. S. 2018. Adrenergic nerve degeneration in bone marrow drives aging of the hematopoietic stem cell niche. Nat Med.

Melhem-Bertrandt, A., Chavez-Macgregor, M., Lei, X., Brown, E. N., Lee, R. T., Meric-Bernstam, F., Sood, A. K., Conzen, S. D., Hortobagyi, G. N. \& Gonzalez-Angulo, A. M. 2011. Betablocker use is associated with improved relapse-free survival in patients with triple-negative breast cancer. J Clin Oncol, 29, 2645-52.

Nissen, M. D., Sloan, E. K. \& Mattarollo, S. R. 2018. beta-Adrenergic Signaling Impairs Antitumor CD8(+) T-cell Responses to B-cell Lymphoma Immunotherapy. Cancer Immunol Res, 6, 98-109.

Pon, C. K., Lane, J. R., Sloan, E. K. \& Halls, M. L. 2016. The beta2-adrenoceptor activates a positive cAMP-calcium feedforward loop to drive breast cancer cell invasion. Faseb j, 30, 1144-54.

Powe, D. G., Voss, M. J., Zanker, K. S., Habashy, H. O., Green, A. R., Ellis, I. O. \& Entschladen, F. 2010. Beta-blocker drug therapy reduces secondary cancer formation in breast cancer and improves cancer specific survival. Oncotarget, 1, 628-38.

Shaashua, L., Shabat-Simon, M., Haldar, R., Matzner, P., Zmora, O., Shabtai, M., Sharon, E., Allweis, T., Barshack, I., Hayman, L., Arevalo, J. M. G., Ma, J., Horowitz, M., Cole, S. W. \& Ben-Eliyahu, S. 2017. Perioperative COX-2 and \&amp;beta;-adrenergic blockade improves metastatic biomarkers in breast cancer patients in a phase-II randomized trial. Clinical Cancer Research.

Sloan, E. K., Priceman, S. J., Cox, B. F., Yu, S., Pimentel, M. A., Tangkanangnukul, V., Arevalo, J. M. G., Morizono, K., Karanikolas, B. D. W., Wu, L., Sood, A. K. \& Cole, S. W. 2010. The Sympathetic Nervous System Induces a Metastatic Switch in Primary Breast Cancer. Cancer Research, 70, 7042-7052.

Sood, A. K., Armaiz-Pena, G. N., Halder, J., Nick, A. M., Stone, R. L., Hu, W., Carroll, A. R., Spannuth, W. A., Deavers, M. T., Allen, J. K., Han, L. Y., Kamat, A. A., Shahzad, M. M. K., Mcintyre, B. W., Diaz-Montero, C. M., Jennings, N. B., Lin, Y. G., Merritt, W. M., Degeest, K., Vivas-Mejia, P. E., Lopez-Berestein, G., Schaller, M. D., Cole, S. W. \& Lutgendorf, S. K. 2010. Adrenergic modulation of focal adhesion kinase protects human ovarian cancer cells from anoikis. The Journal of Clinical Investigation, 120, 1515-1523.

Sorensen, G. V., Ganz, P. A., Cole, S. W., Pedersen, L. A., Sorensen, H. T., Cronin-Fenton, D. P., Garne, J. P., Christiansen, P. M., Lash, T. L. \& Ahern, T. P. 2013. Use of beta-blockers, angiotensin-converting enzyme inhibitors, angiotensin II receptor blockers, and risk of breast cancer recurrence: a Danish nationwide prospective cohort study. J Clin Oncol, 31, 2265-72.

Szpunar, M. J., Belcher, E. K., Dawes, R. P. \& Madden, K. S. 2016. Sympathetic innervation, norepinephrine content, and norepinephrine turnover in orthotopic and spontaneous models of breast cancer. Brain Behav Immun, 53, 223-233.

Thaker, P. H., Han, L. Y., Kamat, A. A., Arevalo, J. M., Takahashi, R., Lu, C., Jennings, N. B., Armaiz-Pena, G., Bankson, J. A., Ravoori, M., Merritt, W. M., Lin, Y. G., Mangala, L. S., Kim, T. J., Coleman, R. L., Landen, C. N., Li, Y., Felix, E., Sanguino, A. M., Newman, R. A., Lloyd, M., Gershenson, D. M., Kundra, V., Lopez-Berestein, G., Lutgendorf, S. K., Cole, S. W. \& Sood, A. K. 2006. Chronic stress promotes tumor growth and angiogenesis in a mouse model of ovarian carcinoma. Nat Med, 12, 939-44.

Uphoff, C. C. \& Drexler, H. G. 2002. Comparative PCR analysis for detection of mycoplasma infections in continuous cell lines. In Vitro Cell Dev Biol Anim, 38, 79-85. 
Venneri, M. G. \& Del Rio, G. 2004. Systematic study of long-term stability of 3,4dihydroxyphenylglycol in plasma for subsequent determination with liquid chromatography. J Chromatogr B Analyt Technol Biomed Life Sci, 802, 247-55.

Watkins, J. L., Thaker, P. H., Nick, A. M., Ramondetta, L. M., Kumar, S., Urbauer, D. L., Matsuo, K., Squires, K. C., Coleman, R. L., Lutgendorf, S. K., Ramirez, P. T. \& Sood, A. K. 2015. Clinical impact of selective and nonselective beta-blockers on survival in patients with ovarian cancer. Cancer, 121, 3444-51. 


\section{FIGURE LEGENDS}

Figure 1. Splanchnic denervation abrogates circulating epinerphine levels. Catecholamines were quantified in plasma by HPLC 4 days after denervation surgery. PNMT: Phenylethanolamine $\mathrm{N}$-methyltransferase; ${ }^{*} p<0.05$

Figure 2. Effect of stress on circulating norepinephrine and epinephrine levels.

Catecholamines were quantified in plasma from denervated mice and sham-operated mice after three days of repeated daily restraint or home-cage conditions. $* p<0.05$

Figure 3. Splanchic denervation has no impact on stress-enhanced cancer growth or metastasis in MDA-MB-231 ${ }^{\mathrm{HM}}$ breast cancers. Mice with bilateral splanchnic denervation or sham-operated mice were injected with MDA-MB-231 ${ }^{\mathrm{HM}}$ cells into the $4^{\text {th }}$ left mammary fatpad. A. Primary tumor growth was monitored by caliper. B. Development of distant metastasis was quantified by longitudinal non-invasive bioluminescence imaging. C. Representative in vivo imaging of metastasis in lymph node and lung on day 35 of tumor growth.

Figure 4. Cancer growth and metastasis of 66cl4 mammary tumors is not affected by splanchic denervation. Balb/c mice with bilateral splanchnic denervation or sham-operated mice were injected with $66 \mathrm{cl} 4$ cells into the $4^{\text {th }}$ left mammary fatpad and exposed to daily restraint stress. A. Primary tumor growth was monitored by caliper. B. Development of distant metastasis was quantified by longitudinal non-invasive bioluminescence imaging.

Supplementary Figure 1. Splanchnic denervation did not cause catecholamine degradation. Dihydroxyphenylglycol was quantified in plasma from denervated mice and sham-operated mice after three days of repeated daily restraint or home-cage conditions. 
Norepinephrine



Epinephrine

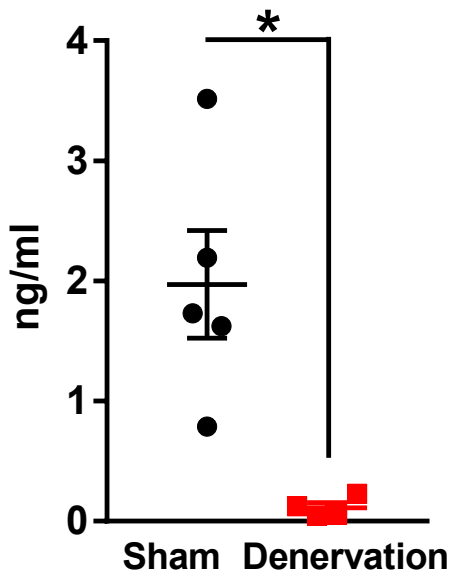

Figure 1 
A



B

Norepinephrine

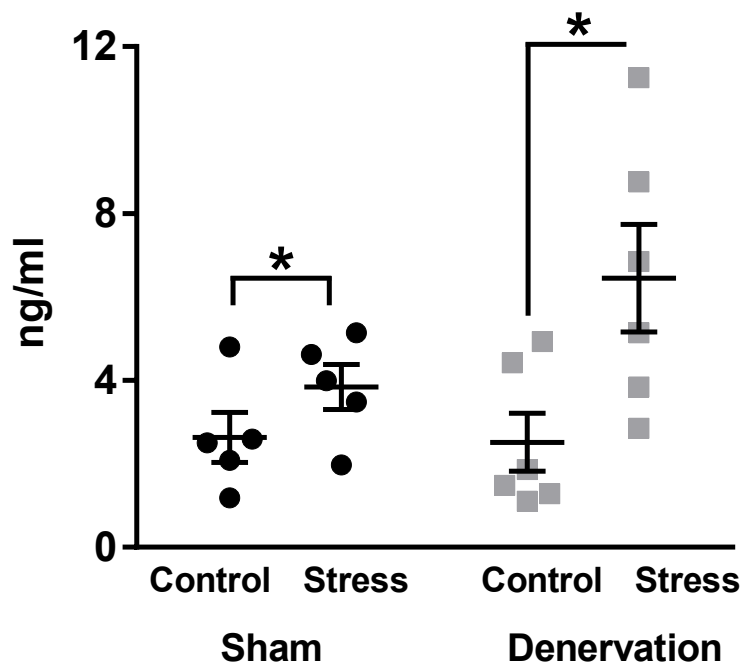


A

MDA-MB-231 primary tumor growth



B

\section{MDA-MB-231 metastasis}



C



\section{Figure 3}


A $66 \mathrm{cl} 4$ primary tumor growth

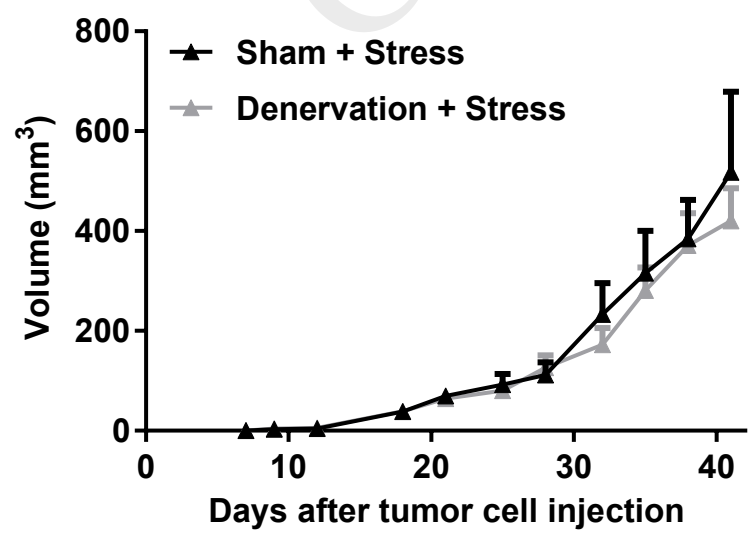

B

$66 \mathrm{cl} 4$ metastasis



\section{Figure 4}




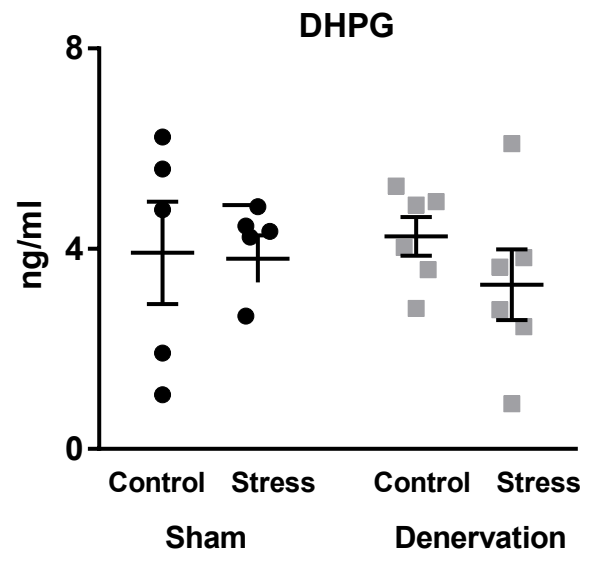

\section{Supplementary Figure 1}

